\title{
Disfonia akibat polip pita suara
}

Ade Asyari, Novialdi, Fachzi Fitri, Nur Azizah

Bagian THTL-KL Fakultas Kedokteran Universitas Andalas

Korespondensi: Ade Asyari, email: adeasyari2@gmail.com

\begin{abstract}
Abstrak
Disfonia merupakan gejala utama disebabkan adanya kelainan pada pita suara. Kelainan bisa berupa lesi jinak seperti polip pita suara, sering terjadi karena fonotrauma yang disebabkan vocal abuse. Polip pita suara yang tidak hilang dengan terapi konservatif maka pembedahan merupakan pilihan terapi. Tujuan: Memahami penyebab dan penanganan yang tepat pasien dengan disfonia. Laporan Kasus: Dilaporkan satu kasus polip pita suara kanan pada seorang perempuan usia 30 tahun dengan keluhan utama disfonia. Disfonia pada pasien membaik setelah dilakukan terapi pembedahan. Kesimpulan: Polip pita suara merupakan salah satu lesi jinak dengan keluhan utama disfonia. Disfonia karena polip pita suara umumnya membaik setelah polip diangkat.
\end{abstract}

Kata kunci: disfonia; fonotrauma; vocal abuse; polip pita suara

\section{Abstract}

Dysphonia are the main symptom caused by abnormality at the vocal cord. An abnormality can be a benign lesion such as vocal cord polyp, commonly caused by vocal abuse phono trauma. Vocal cord polyp that failed with conservative treatment, surgery is the choice of treatment. Objective: Understanding causes and proper treatment of patient with dysphonia. Case reports: A case of right vocal cord polyp in 30-year-old woman had been reported. Dysphonia was getting better after surgery treatment. Conclusion: Vocal cord polyp is one of benign lesion with dysphonia as chief complain. Dysphonia due to vocal cord polyp commonly improved after the lesion was removed.

Keywords: dysphonia; phono trauma; vocal abuse; vocal cord polyp 


\section{PENDAHULUAN}

Disfonia merupakan perubahan kualitas suara pada nada maupun intensitas baik karena gangguan fungsional ataupun organik, kelainan sistemik ataupun lokal. Disfonia fungsional merupakan disfonia tanpa ditemukan kelainan organik, disfonia ini terjadi karena abnormalitas tonus otot pita suara yang menimbulkan gangguan dan irreguler osilasi, penyebab tersering karena faktor kebiasaan bersuara (vocal abuse), gangguan emosional dan psikogenik. Sedangkan disfonia organik timbul apabila adanya kelainan organik pita suara, misalnya laringitis akut atau kronis, tumor jinak (polip pita suara, nodul, Reinke's edema, kista dan papiloma), tumor ganas, trauma laring, presbifonia. Selain itu disfonia dapat terjadi karena internal disease (refluks laringofaringeal, tuberkulosis, limfoma) dan disfonia karena penyakit neurologi (parese pita suara). ${ }^{1,2}$

Pilihan pengobatan pada disfonia tergantung gangguan yang menyebabkannya. Terapi yang dilakukan bisa berupa terapi konservatif dan pembedahan. Disfonia fungsional umumnya sembuh dengan terapi konservatif berupa memperbaiki faktor risiko dan voice therapy, namun apabila disfonia tidak diobati dapat berkembang menjadi disfonia organik. ${ }^{1,2}$

Disfonia bisa berupa suara serak, kasar, suara yang keluar terlampau keras atau terlampau lemah, puncak suara yang pecah. Untuk menentukan seorang pasien mengalami disfonia bisa dengan mendengar suara, mengobservasi pasien dan memeriksa laring dengan kaca laring. Pemeriksaan tambahan sering dilakukan untuk mendapat hasil pemeriksaan objektif misalnya glottografi, Stroboscopic Imaging, pengukuran aerodinamik, dan akustik. ${ }^{2,3}$

Pemeriksaan secara subjektif dapat dilakukan dengan metode GRBAS yaitu dengan mendengarkan suara dan menilai derajat penyimpangan (grade of deviance), kekasaran (roughness), breathiness, astenis (kelemahan) dan kekakuan (strain). Skala penilaian adalah $0-3 .^{3}$

Glottografi merupakan suatu pemeriksaan yang menggunakan sektor fisiologis untuk merekam jumlah cahaya yang ditransiluminasi laring sewaktu bergetar (Photoglottgraphy/PGG) atau tingkat satuan pita suara (Electroglottography/EGG). Sinyal PGG dan EGG saling melengkapi, dimana PGG menunjukkan tingkat pembukaan pita suara dan EGG menunjukkan penutupan pita suara. Perubahan gelombang ini diobservasi untuk menggambarkan perubahan getaran laring yang berhubungan dengan lesi massa atau keadaan kekakuan yang asimetris. Glottografi adalah tes non invasif dan analisa sinyal dapat diolah komputer. Penilaian yang didapat hanya jumlah total getaran dari kedua pita suara, sehingga lokasi anatomis yang tepat dari lesi tidak dapat terlihat hanya dengan PGG dan EGG saja. ${ }^{2,3}$

Stroboscopic Imaging membantu dalam mencatat dan memperjelas berbagai lesi 
pada laring. Laringoskop indirek hanya memeriksa keadaan statis dan pergerakan pita suara secara kasar. Saat fonasi stroboskopi dapat memeriksa secara detail asal getaran dari pita suara. Stroboskopi sangat berguna dalam mendiagnosis kelainan suara dan dapat mendiagnosis secara dini lesi dini kanker glotis., ${ }^{2,3}$

Peralatan aerodinamik dapat digunakan untuk mengukur hantaran udara melalui glotis dan tekanan di bawah glotis. Nilai estimasi tekanan sub glotis dan aliran udara translaringeal rata-rata, dapat digunakan untuk menghitung tahanan glotis. Pasien dengan paralisis biasanya menunjukkan rendahnya tahanan glotis. Pasien dengan suara kasar dan adanya lesi yang dapat meningkatkan kekakuan pita suara, biasanya menunjukkan peningkatan resistensi glotis. ${ }^{2,3}$

Pengukuran akustik sangat berguna karena memiliki kemampuan menghitung kuantitas tingkat kekasaran suara. Walaupun telinga orang yang terlatih kemungkinan dapat dengan sensitif menganalisis suara, tetapi pengukuran akustik mempunyai keuntungan, karena dapat menjamin dokumentasi kuantitatif tingkat variasi dari yang normal.2,3

Lebih dari $50 \%$ pasien dengan keluhan disfonia disebabkan oleh lesi jinak pada pita suara.4 Polip pita suara merupakan salah satu lesi jinak yang sering terjadi dan tidak jarang membutuhkan terapi pembedahan. Faktor penyebab yang sering adalah vocal abuse (penggunaan suara berlebihan, berteriak, berbicara keras) biasanya pada voice professional seperti guru, dosen, dan penceramah. ${ }^{4-8}$ Polip pita suara sering terjadi pada laki-laki dibandingkan perempuan dengan perbandingan 2:1 dan bisa ditemukan pada semua usia, biasanya pada usia dewasa antara umur 20-60 tahun. ${ }^{5}$

Pembedahan merupakan pilihan terapi pada polip pita suara, bila terapi konservatif gagal. Tujuan utama pembedahan adalah melindungi ligamen pita suara sehingga proses vibrasi mengalami perbaikan. ${ }^{5,6,9}$ Pembedahan dapat dilakukan secara konvensional atau dengan menggunakan Light Amplification by the Stimulating Emission of Radiation (LASER).6,9

\section{Anatomi dan Fisiologi Laring}

Anatomi laring terbagi atas supra glotis, glotis dan sub glotis. Kerangka laring terdiri dari tulang hioid dan sejumlah tulang rawan yang saling berhubungan melalui ligamen, membran, otot intrinsik dan ekstrinsik. Struktur anatomi yang paling penting untuk produksi suara adalah pita suara. ${ }^{10-12}$

Pita suara sebagai organ fonasi terdiri atas komponen body dan cover. Komponen body dibentuk oleh dua otot tiroaritenoid yang mengandung serat aduksi dan abduksi yang menentukan panjang, kontur, dan bentuk glotis bila pita suara menutup dan juga sebagai pengatur ketegangan lapisan mukosa pita suara sehingga lebih fleksibel dan mudah bervibrasi. Gelombang vibrasi mukosa dapat dilihat dengan menggunakan video stroboskopi laring, yaitu untuk menilai 
undulasi dari permukaan inferior (bibir bawah) ke superior (bibir atas) pita suara. Area antara bagian inferior dan superior pita suara sebagai penentu volume dan perubahan nada suara. Bila ada lesi di antara daerah tersebut maka volume dan nada suara yang dihasilkan akan berubah, tergantung ukuran dan lokasi lesi tersebut. ${ }^{6,11,12}$

Komponen cover terdiri dari lapisan luar yang diliputi epitel skuamosa berlapis, lapisan dalam dan lamina propria. Lamina propria terbagi atas 3 lapisan yaitu superfisial, intermedia dan profunda (Gambar 1).

Lapisan superfisial dikenal juga dengan ruang Reinke yang tersusun atas jaringan ikat longgar sehingga menyebabkan lapisan ini lebih fleksibel dan mudah bergerak. Lapisan intermedia dan profunda bersama-sama membentuk ligamen vokal. ${ }^{10-12}$

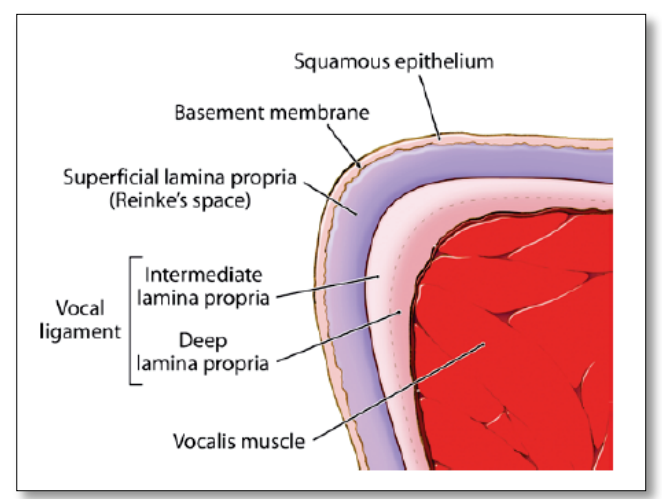

Gambar 1. Lapisan pita suara ${ }^{10}$

Kebanyakan lesi jinak mukosa pita suara ditemukan pada lapisan superfisial, jika lesi berada di permukaan superior pita suara yang jauh dari tepi daerah vibrasi mungkin tidak mengganggu suara walaupun lesinya besar. Hal ini penting untuk menentukan jenis intervensi bedah yang dilakukan. ${ }^{6,12}$

\section{Patofisiologi Disfonia}

Fungsi laring adalah sebagai proteksi jalan nafas, respirasi dan fonasi. ${ }^{4-8}$ Saat inspirasi pita suara abduksi dan saat ekspirasi aduksi. Sebelum fonasi, pita suara abduksi secara cepat agar udara masuk ke saluran nafas (fase inspirasi sebelum fonasi) selanjutnya pita suara aduksi karena berkontraksinya otot krikoaritenoid lateral. Suara dihasilkan mulai dari udara paru-paru yang dikeluarkan melewati pita suara yang aduksi sampai menimbulkan vibrasi berulang dari pita suara (osilasi). Saat pita suara menutup, udara dari paru melewati daerah yang sempit, akan mengakibatkan tekanan negatif pada daerah sekitarnya, sehingga mukosa pita suara seperti menarik satu sama lain (efek Bernauli), saat tekanan udara sub glotis meningkat (di bawah pita suara yang aduksi) hingga mencapai tingkat penekanan pada tahanan pada pita suara menyebabkan pita suara terpisah lalu merangsang terjadinya siklus vibrasi pita suara, terjadinya vibrasi ini yang menimbulkan terbentuknya suara. ${ }^{11,12}$

Vibrasi pita suara terdiri dari gerakan dasar dan relatif. Gerakan dasar yaitu gerakan mediolateral dari otot vokalis dan ligamen vokalis. Gerakan relatif yaitu gerakan dari mukosa superfisial terhadap otot vokalis selama fonasi. Gerakan relatif ini menghasilkan gelombang pada permukaan epitel yang disebut "traveling wave motion" (Gambar 2). Kelainan yang 
menimbulkan gangguan vibrasi pita suara, abnormalitas tonus otot, penutupan pita suara yang tidak komplit, paralisis pita suara, atrofi pita suara dapat menimbulkan disfonia. $^{2,12}$

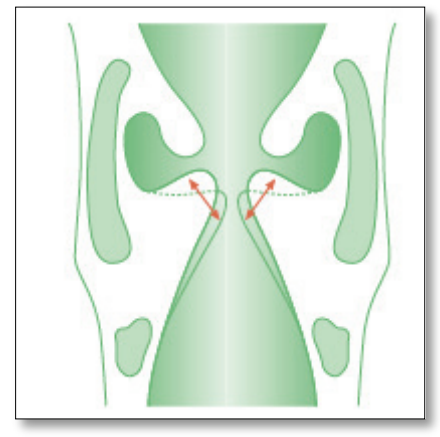

a

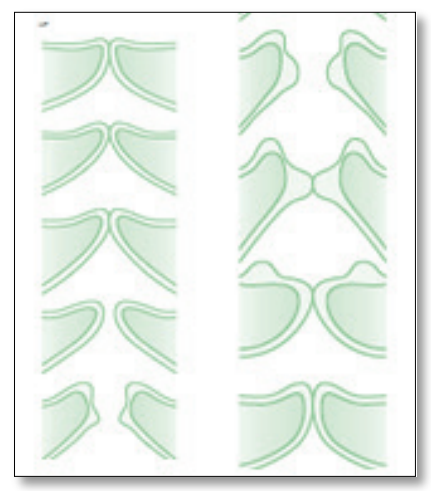

b

Gambar 2. a. Gerakan dasar; b. Travelling wave motion ${ }^{2}$

\section{Polip Pita Suara}

Polip pita suara adalah tumor jinak pada jaringan lunak sub epitel atau lamina propria dengan disfonia sebagai gejala utama. ${ }^{4,6,7}$ Faktor yang dapat menjadi pemicu terjadinya polip pita suara selain vocal abuse adalah merokok, alergi, infeksi kronis saluran nafas atas dan refluks laringofaringeal. ${ }^{5,8}$

Diagnosis polip pita suara ditegakkan berdasarkan anamnesis, pemeriksaan telinga, hidung, dan tenggorok untuk mencari faktor risiko serta pemeriksaan laringoskopi dengan atau tanpa videostroboskopi. Diagnosis pasti ditegakkan dengan pemeriksaan patologi anatomi. $^{4-7}$

Pada anamnesis, pasien mengeluhkan suara serak yang dirasakan terus menerus dan lebih dirasakan saat penggunaan suara yang berlebihan. Keluhan kadang disertai rasa lelah bila berbicara. Pada polip yang ukuran besar bisa menimbulkan batuk iritatif dan bila sangat besar atau multipel dapat menimbulkan sumbatan jalan nafas. $^{1,5,7}$

Pemeriksaan fisik yaitu pemeriksaan laring dengan kaca laring atau laringoskop dengan atau tanpa stroboskopi. Polip pita suara bisa tampak berwarna putih keabuabuan, transparan, edematous dan bisa juga berwarna kemerahan. Bisa berbentuk bulat, panjang, irreguler atau polipoid., ${ }^{4,7}$ Predileksinya lebih dari $80 \%$ unilateral dan $20 \%$ bilateral atau multipel. Lesi ini biasanya terletak di sepertiga anterior atau sepertiga tengah. ${ }^{5}$ Gambaran kelainan lain pada pita suara yang mirip dengan polip pita suara adalah:

1. Reinke's edema. Lokasi bilateral atau unilateral dengan adanya edema pada pita suara. Pemeriksaan mikroskopis tampak edema pada membran basal dari epitel berlapis gepeng, jaringan sub epitel dengan cairan edema terdapat pada jaringan ikat longgar dan ekstravasasi dari sel darah merah serta terjadi peningkatan 
penebalan dari dinding pembuluh darah pada submukosa. ${ }^{1,7}$

2. Nodul pita suara, selalu bilateral, sering simetris. Lokasi lesi pada bagian anterior atau sepertiga tengah dari pita suara, bergerak saat berbicara. Secara mikroskopis sama dengan Reinke's edema, tapi tidak terdapat bagian yang edema dan peningkatan penebalan pembuluh darah. ${ }^{6}$

3. Kista pita suara, bisa unilateral atau bilateral Terbentuk akibat tersumbatnya kelenjar mukosa (mucous gland). Kista dapat berisi cairan serosa, mukoid atau sisa epitel. Kista dapat terletak di lamina propria superfisial, menempel pada ligamentum vokalis. ${ }^{1,6,7}$

Terapi polip pita suara adalah terapi konservatif dan pembedahan. Terapi konservatif saja yaitu dengan medikamentosa dan voice therapy sering tidak berhasil. Pembedahan dapat dilakukan dengan teknik konvensional atau menggunakan LASER. Prinsip pembedahan adalah preservasi maksimal mukosa normal agar terjadi penyembuhan luka yang spontan dan mencegah terbentuknya jaringan parut. Teknik bedah mikrolaringoskopi dengan LASER memiliki angka keberhasilan tinggi terutama untuk pembedahan lesi yang sulit, keakuratan pembedahan dapat mencapai 0,1 $\mathrm{mm}$, dapat menghentikan perdarahan serta edema pasca operasi jarang terjadi. ${ }^{5,6,9}$

\section{LAPORAN KASUS}

Seorang pasien perempuan 30 tahun datang ke poliklinik Telinga Hidung Tenggorok Kepala dan Leher (THT-KL) RSUP Dr. M. Djamil Padang pada tanggal 22 Desember 2015 dengan keluhan utama suara serak dirasakan sejak 8 bulan yang lalu, terus menerus, dan bertambah berat bila pasien banyak bicara. Pasien merasa lelah saat bicara dan sulit untuk mengucapkan kalimat yang panjang. Tidak ada sesak nafas. Tidak ada demam. Riwayat nyeri menelan tidak ada. Riwayat merokok dan konsumsi alkohol tidak ada. Riwayat nyeri ulu hati, sering mendehem, rasa panas di dada tidak ada. Riwayat alergi tidak ada. Pasien bekerja sebagai guru sekolah dasar selama 7 tahun, sudah berobat ke dokter spesialis THT-KL selama 4 bulan karena keluhan tersebut, pasien mendapat 3 macam obat makan (pasien tidak mengetahui nama obat), karena tidak ada perubahan, dirujuk ke RSUP Dr. M. Djamil Padang.

Pada pemeriksaan telinga, hidung dan tenggorok dalam batas normal. Pada laringoskopi indirek dan telelaringoskopi kaku didapatkan epiglotis dan aritenoid tenang, plika ventrikularis dan vokalis pergerakan simetris, pada bagian $1 / 3$ anterior pita suara kanan tampak massa putih keabuan, permukaan licin, rima glotis terbuka, sinus piriformis standing secretion tidak ada. 

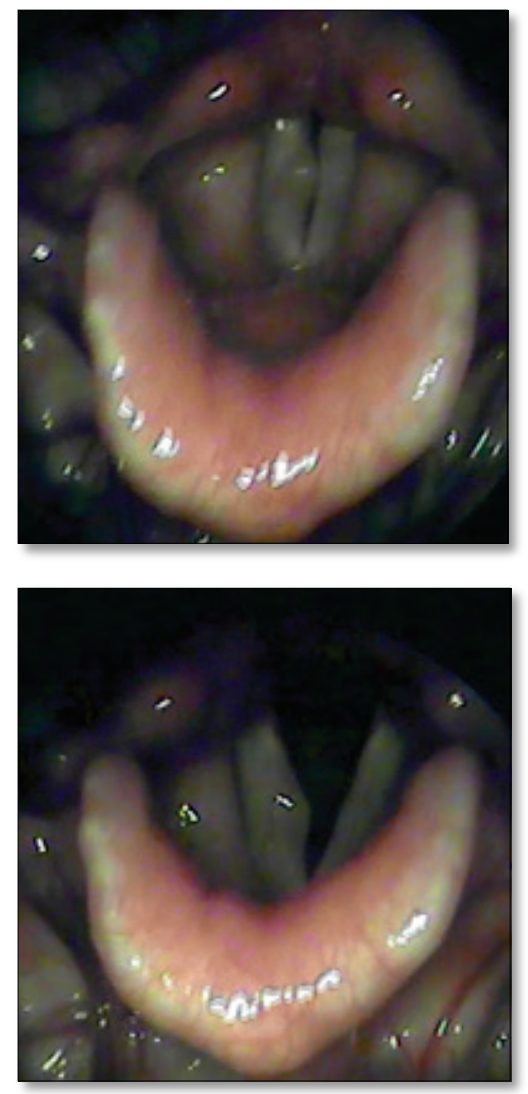

Gambar 3. Gambaran telelaringoskopi kaku pre operasi.

Pasien didiagnosis dengan tumor pita suara kanan suspek polip pita suara dengan diagnosis banding kista pita suara kanan (gambar 3). Pasien direncanakan untuk ekstirpasi tumor dengan menggunakan LASER.

Pada tanggal 15 Januari 2016 dilakukan ekstirpasi tumor pita suara kanan menggunakan LASER dioda dalam narkose umum. Setelah dilakukan tindakan pemasangan laringoskop Kleinsasser, evaluasi pita suara tampak massa tumor keabuan, permukaan licin dibagian 1/3 anterior pita suara kanan. Dilakukan fiksasi massa tumor dengan forsep bengkok kanan lalu massa tumor direseksi dengan microscissor. Dilakukan pemasangan pack kasa basah pada sub glotis. Dilakukan pembersihan massa tumor dengan LASER metode kontak dan non kontak. Asap LASER dihisap dengan suction. Pack kasa basah di sub glotis dikeluarkan. Laringoskop Kleinsasser dikeluarkan pelan-pelan. Operasi selesai. Jaringan massa tumor dikirim ke laboratorium patologi anatomi. Pasien diberikan terapi injeksi Sefoperazon $2 \times 1$ gram (iv), injeksi Deksametason $3 \times 5 \mathrm{mg}$ (iv), Tramadol $10 \mathrm{mg}$ dalam infus $500 \mathrm{cc}$ Ringer Laktat 8 jam/kolf, injeksi Ranitidin $50 \mathrm{mg}$ (iv), pasien tidak boleh berbicara selama 1 minggu.

Satu hari pasca operasi, keluar darah dari mulut tidak ada, sesak nafas tidak ada, demam tidak ada, batuk tidak ada, mual muntah tidak ada. Pasien boleh pulang diberikan terapi oral Cefixime tablet $2 \times 200$ mg dan Ibuprofen tablet $3 \times 400$ mg. Pasien diberikan edukasi: tidak boleh berbicara selama 1 minggu; hindari makanan pedas, bersifat iritatif, minum air panas atau dingin, paparan asap rokok; dan dianjurkan banyak minum). Pasien kontrol 1 minggu lagi.

Kontrol pertama, tanggal 22 Januari 2016 (1 minggu pasca operasi). Pasien membawa hasil laboratorium patologi anatomi dengan hasil: tampak potongan jaringan dengan permukaan dikelilingi epitel berlapis gepeng yang mengalami hiperplasia, inti dalam batas normal. Stroma jaringan ikat mengandung kapilerkapiler yang hiperemis. Kesan: polip pita suara. Keluhan pasien yaitu batuk yang dirasakan hilang timbul, demam tidak ada, 
sesak nafas tidak ada, mual-muntah tidak ada.

Pada laringoskop indirek dan telelaringoskopi kaku didapatkan epiglotis dan aritenoid tenang, plika ventrikularis dan plika vokalis pergerakan simetris, luka operasi di $1 / 3$ anterior pita suara kanan sedikit hiperemis, massa tidak ada, rima glotis terbuka, sinus piriformis standing secretion tidak ada. Diagnosis pasien pasca ekstirpasi polip pita suara kanan hari ke-7. Terapi Cefixime tablet 2×200 mg, Tinoridin HCL kapsul $3 \times 1$ dan edukasi pasien. Pasien kontrol 1 minggu lagi.

Kontrol ke-2, tanggal 29 Januari 2016 (dua minggu pasca operasi). Suara serak masih dirasakan pasien. Batuk tidak ada. Demam tidak ada. Sesak nafas tidak ada. Mual muntah tidak ada. Pada laringoskop indirek dan telelaringoskopi kaku didapatkan epiglotis dan aritenoid tenang, plika ventrikularis dan plika vokalis pergerakan simetris, luka operasi di $1 / 3$ anterior pita suara kanan tenang, massa tidak ada, rima glotis terbuka, sinus piriformis standing secretion tidak ada. Diagnosis pasca ekstirpasi polip pita suara kanan minggu ke-2. Pasien tetap diberikan edukasi dan kontrol dua minggu lagi.

Kontrol ke-3, tanggal 23 Februari 2016 (1,5 bulan pasca operasi). Suara serak dirasakan membaik, batuk dan demam tidak ada. Sesak nafas tidak ada. Laringoskop indirek dan telelaringoskopi kaku didapatkan epiglotis dan aritenoid tenang, plika ventrikularis dan plika vokalis pergerakan simetris, luka operasi di 1/3 anterior pita suara kanan tenang, massa tidak ada, rima glotis terbuka, sinus piriformis standing secretion tidak ada. Diagnosis pasien pasca ekstirpasi polip pita suara kanan 1,5 bulan. Pasien dianjurkan kontrol 1 bulan lagi.

Kontrol ke-4, tanggal 1 April 2016 (3 bulan pasca operasi). Suara serak tidak dirasakan lagi. Demam tidak ada. Sesak nafas tidak ada. Mual muntah tidak ada. Pada laringoskop indirek dan telelaringoskopi kaku didapatkan epiglotis dan aritenoid tenang, plika ventrikularis dan plika vokalis pergerakan simetris, luka operasi tenang, massa tidak ada, rima glotis terbuka, sinus piriformis standing secretion tidak ada. Diagnosis pasca ekstirpasi polip pita suara kanan bulan ke-3 (gambar 4).
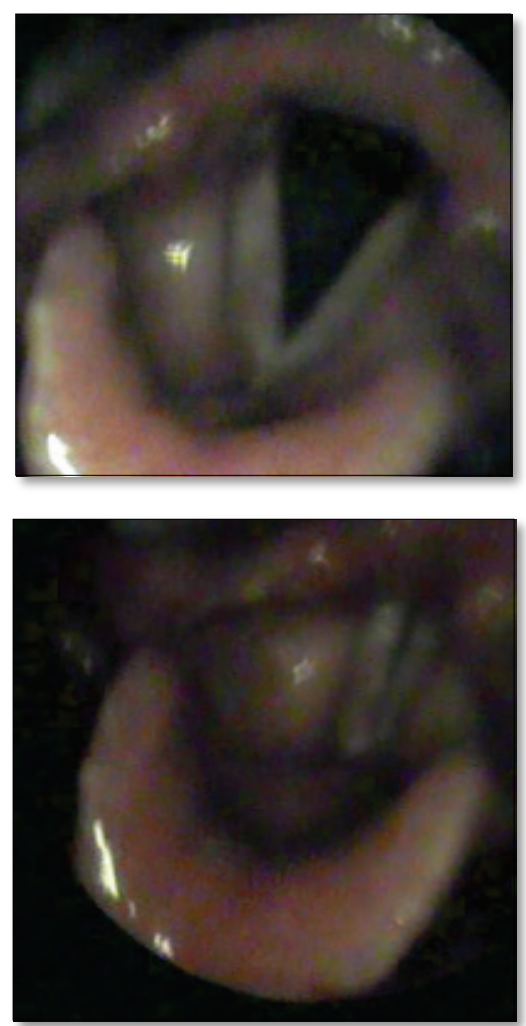

Gambar 4. Kontrol 3 bulan pasca operasi reseksi polip pita suara kanan 


\section{PEMBAHASAN}

Telah dilaporkan satu kasus pasien perempuan usia 30 tahun, dengan keluhan utama disfonia. Pasien bekerja sebagai seorang guru selama 7 tahun. Berdasarkan anamnesis, pemeriksaan fisik dan pemeriksaan patologi anatomi pasien didiagnosis dengan polip pita suara.

Pada kasus, disfonia terjadi pada perempuan, 30 tahun dan berprofesi seorang guru. Sesuai dengan penelitian Martins dkk ${ }^{8}$ yaitu pada 2019 pasien disfonia, didapatkan bahwa disfonia umumnya terjadi pada usia dewasa yaitu umur 20-60 tahun, lebih banyak pada perempuan dan timbul berhubungan dengan profesi, terutama profesi yang tergantung suara misalnya guru, marketing, penyanyi dan penceramah.

Pada kasus ini disfonia muncul pada pasien yang berprofesi guru. Profesi guru, merupakan profesi yang banyak menggunakan suara (vocal abuse) dan berisiko tinggi untuk mengalami disfonia. Hal ini dikaitkan dengan lingkungan kerja yang bising sehingga membutuhkan intensitas suara yang tinggi, polutan (debu dan serbuk kapur tulis) dan bekerja sampai beberapa jam tanpa istirahat. ${ }^{8,13}$

Pasien didiagnosis dengan polip pita suara. Polip pita suara merupakan suatu lesi yang umumnya terbentuk karena vocal abuse. Pada vocal abuse terjadi proses fonotrauma, yaitu trauma vibratori pada membran pita suara yang menimbulkan gangguan mikro sirkulasi, hancurnya pembuluh darah superfisial dan menimbulkan hemoragik pada pita suara yang merangsang terjadinya reaksi inflamasi lalu terbentuk suatu lesi neovaskular. ${ }^{4,7}$ Soni $\mathrm{DH}^{14}$, pada penelitiannya menjelaskan bahwa lesi yang terbentuk karena fonotrauma bisa berupa nodul, polip, kista serta Reinke's edema pada pita suara.

Pasien diterapi dengan pembedahan setelah berobat ke dokter spesialis THT-KL di daerahnya selama 4 bulan dan tidak ada perubahan. Pada pasien ditemukan massa tumor pada pita suara yang diduga polip atau kista. Sebaiknya sebelum memutuskan terapi bedah selain terapi medikamentosa pada pasien dianjurkan untuk voice therapy. Pada pasien tidak dilakukan karena sarana dan prasarana belum ada. Efektivitas voice therapy pada pasien dengan massa tumor di pita suara tergantung jenis massa tumornya dan konsistensi pasien dalam melakukannya. Polip pita suara dengan terapi konservatif saja jarang berhasil. ${ }^{4-6,9,15}$ Voice therapy efektif untuk mengurangi kebiasaan bicara yang merugikan dan untuk kelainan suara non organik (disfonia fungsional) dan nodul pita suara. ${ }^{16-18}$

Pasien dianjurkan untuk tidak bersuara selama 1 minggu dan istirahat suara (berbicara sedikit-sedikit, berbicara dengan nada rendah) selama 1 bulan. Untuk lama waktu pasien istirahat suara belum ada ketetapan pasti, umumnya dianjurkan 7-10 hari pasca ekstirpasi akan memberikan suara yang kembali baik dalam 1-2 bulan. ${ }^{5}$ Istirahat suara bertujuan untuk membantu agar penyembuhan 
mukosa pita suara tidak terganggu sehingga tidak terbentuk jaringan parut yang dapat menimbulkan disfonia persisten pasca operasi. ${ }^{18,19}$ Penelitian Lilin dkk16 pada pasien pasca phonosurgery polip pita suara, dilakukan rehabilitasi suara dengan cara pasien dianjurkan diam (tidak bersuara) selama 7 hari dan istirahat suara selama 1 bulan. Rehabilitasi suara berfungsi untuk mengoptimalkan penyembuhan luka operasi dan memulihkan fungsi vokal pita suara. Behrman ${ }^{17}$, menjelaskan banyak ahli THT$\mathrm{KL}$ merekomendasikan istirahat suara selama 7 hari karena penyembuhan mukosa pita suara berlangsung selama 7 hari dan penyembuhan optimal selama 1 bulan.

Pasca operasi suara serak pasien dirasakan membaik, hal ini karena gangguan vibrasi dan penutupan pita suara tidak ada lagi. Disfonia yang persisten bisa terjadi bila saat operasi mukosa pita suara normal terangkat sangat banyak sehingga timbul jaringan parut, selain itu bisa karena pasien tidak melakukan istirahat suara dengan adekuat. Lee ${ }^{19}$ pada penelitiannya melakukan latihan suara pasca ekstirpasi polip pita suara, tujuannya untuk menciptakan keseimbangan organ fonasi, memodifikasi kondisi patologi yang ditimbulkan oleh lesi pada pita suara serta mencegah rekurensi polip pita suara. Latihan berupa pasien tidak bersuara selama 1 minggu, istirahat suara 1 bulan, hindari makanan pedas, makanan bersifat iritatif, tidak minum alkohol, merokok, minum air panas atau dingin, mengubah kebiasaan vokal yang buruk, latihan pernafasan.

Terapi pasien dipilih tindakan ekstirpasi polip pita suara dengan teknik LASER dioda. Pembedahan merupakan tindakan pilihan untuk polip pita suara. Tujuan pembedahan adalah untuk menghasilkan pita suara mendekati kondisi normal dan fungsi bicara dengan prognosis yang baik yaitu untuk kembali pada suara normal. ${ }^{5,6}$ LASER dioda berfungsi untuk mengontrol perdarahan di daerah operasi sehingga dapat mempercepat waktu pemulihan, melindungi anatomi organ yang diperlukan dan juga fungsi dari organ tersebut. Teknik non kontak digunakan untuk meminimalkan kerusakan jaringan dan mempertahankan struktur jaringan. ${ }^{6,9}$

Follow up pasien dilakukan 1 minggu setelah tindakan, dilanjutkan setelah 1 bulan tindakan dan kontrol pasien tetap dilakukan sampai bulan ketiga setelah tindakan. Literatur menyebutkan bahwa waktu minimal kontrol untuk pasien polip adalah 3 bulan juga untuk Reinke's edema dan kista retensi, 5 bulan untuk sikatrik dan 6 bulan untuk nodul pita suara ${ }^{5}$. Pada follow up, dievaluasi mengenai komplikasi operasi yang bisa terjadi yaitu lesi pada bibir, rongga mulut, orofaring, gigi patah, terbentuknya granuloma yang merupakan komplikasi jarang yang timbul karena trauma pada kartilago aritenoid.6,9 Sedangkan untuk angka rekurensi polip pita suara sangat jarang, terutama apabila pasien dapat menghindari faktor pemicu terjadinya polip pita suara. ${ }^{5}$ 


\section{KESIMPULAN}

Polip pita suara merupakan salah satu lesi jinak dengan keluhan utama disfonia. Salah satu faktor pencetus terjadinya polip pita suara adalah vocal abuse. Disfonia karena polip pita suara umumnya membaik setelah polip diangkat.

\section{DAFTAR PUSTAKA}

1. Reiter R, Hoffman K.T, Pickhard A, Brosch S. Hoarseness causes and treatments. Dtsch Arztebl Int 2015; 112:329-37.

2. Probst R, Grevers G, Iro H. Voice disorders. In :Basic otorhinolaryngology, a step by step learning guide. Thieme; 2006. p.385-95.

3. Dejonckere H.P. Assessment of voice and respiratory function. In: Remacle M, Eckel E.H editors. Surgery of larynx and trachea. Berlin: Springer; 2010. p.11-24.

4. Filho I.M.J, Cavalho B, Mizoguchi M.F, Catani A, Filho M, Malafaia dkk. Characteristics of polypoid lesions in patients undergoing microsurgery of the larynx. Otorhinolaryngol. 2013; 17(3):279-84.

5. Benjamin B. Vocal cord polyps. In: Martin duniz editor. Endolaryngeal surgery. London; 1998. p.237-40.

6. Rosen CA, Ingle JW. Benign vocal fold lesions and phonomicrosurgery. In: Johnson Jonas T, Rosen Clark A, editors Bailey's head and neck surgery otolaryngology fifth ed. Philadelphia Lippincott Inc; 2014. p.989-1003.

7. Wareing $\mathrm{M}$, obholzer R Benign laryngeal lesions. In Lalwani A.K editors. Current diagnosis \& treatment otolaryngology head \& neck surgery. Second ed. McGraw-Hill Companies, Inc; 2008. P.430-36.

8. Martins G.H.R, Amaral A.H, Tavares M.A.H, Martins G.M, Goncalves M.T, Dias H.N, Voice disorders: etiology and diagnosis. J Voice. 2015:1-8.

9. Remacle M. Laser assisted microphonosurgery. In: Remacle M, Eckel E.H editors. Surgery of larynx and trachea. Berlin: Springer; 2010. p.51-55.

10. Rosen A.C, Simpson B.C. Anatomy and physiology of the larynx. In: rosen A.C, Simpson B.C editors. Operative techniques in laryngology: California. Springer; 2008. p.3-8.

11. Sulica L. Voice: anatomy, physiology, and clinical evaluation. In: Johnson Jonas T, Rosen Clark A, editors. Bailey's head and neck surgery otolaryngology. fifth ed. Philadelphia Lippincott Inc; 2014. p.945-55.

12. Izdebski K. Clinical voice assesment: The role\&value of the phonatory function studies. In: Lalwani A.K editors. Current diagnosis \& treatment otolaryngology head \& neck surgery. Second ed. McGraw-Hill Companies, Inc; 2008. P.417-29.

13. Cutiva C.C.L, Vogel I, Burdorf A. Voice disorders in teachers and their associtions with workrelated factors: a systemic review. J.Commun Dis. 2013; 46:143-55.

14. Soni D,H. Gandhi S. Goya M, Shah U. Study of clinical profile of benign laryngeal lesions. Int J of Med sci and public health. 2016; 5(4):456-60. 
15. Cohen SM, Garrett CG. Utility of voice therapy in the management of vocal fold polyps and cysts. Otolaryngol head neck Surg 2007; 136:742-46.

16. Lilin, Nasun, Yang Q, Zhang Y, Shen JI, Shi L,dkk. Effect of voice training in the voice rehabilitation of patients with vocal cord polyps after surgery. Exp. Adn therapeutic med. 2014; 7:877-80.

17. Behrman A, Sulica L. Voice rest after microlaryngoscopy:current opinion and practice. Laryngoscope. 2003; 113(2):182-5.

18. Tang S.S, Thilbeault L.S. Timing of voice therapy: a primary investigation of voice outcomes for surgical benign vocal fold lesion patients. J voice. 2015:1-6.

19. Lee S.Y, Lee H.D,Jeong E.G, Kim W.J, Roh L.J, Choi H.S, Kim Y.S dkk. Treatment efficacy of voice therapy for vocal fold polyps and factors predictive of its efficacy. J Voice. 2016:1-5. 